D:\Nsurg\Nsurg Vol. 25, No. 3, Jul. - Sep., 2021\NS-Editorial Dear Readers-4.Doc P. xi

(A)

\title{
Editorial
}

Dear Readers

Pakistan Journal of Neurological Surgery is recognized by The Higher Education Commission (HEC), Islamabad. The journal has been indexed in multiple International agencies like EuroPub UK, ICI (Index Copernicus), ISSN France, BASE Germany, Cross Ref, Eurasian Index, Asian Digital, PASTIC and PakMediNet.

\section{Sub arachnoid hemorrhage and vasospasm}

Spontaneous sub arachnoid hemorrhage develops vasospasm in the 3-8 days. It should be dealt with conservative symptomatic treatment in this risky phase. Commonest presentation of vasospasm is headache. Usually headache increases with the onset of vasospasm at day 3 and diminishes as the vasospasm subsides after 8-10 days. Surgical interventions like clipping and coiling should be avoided in this period and patients should be given plenty of fluids (hemodilution, hypervolemia and hypertension). This triple $\mathrm{H}$ therapy holds good for asymptomatic vasospasms but were found less effective in symptomatic patients of SAH. Constipation should be avoided. Grade is supported by evidence from placebo-controlled study. There are some guidelines available for the prevention and the treatment of cerebral vasospasms with Nimodipine (oral). The use of triple $\mathrm{H}$ treatment as a preventative measure is a grade $B$ recommendation. The treatment of symptomatic vasospasm with therapeutic hypertensive hypervolemia hemodilution is advised, however no prospective trials are available (grade C recommendation). There is no evidence that antifibrinolytics, steroids, or anticonvulsive prophylaxis should be used routinely. Current prophylaxis and treatment of cerebral vasospasm are still insufficient, according to clinical data, and vigorous triple- $\mathrm{H}-$ therapy is linked to an increased risk of sequelae.

\section{Reference:}

Raabe A, Beck J, Berkefeld J, Deinsberger W, Meixensberger J, Schmiedek P, Seifert V, Steinmetz H, Unterberg A, Vajkoczy P, Werner C. Recommendations for the management of patients with aneurysmal subarachnoid hemorrhage. Zentralblatt fur Neurochirurgie. 2005;66(2):7991.

DOI 10.36552/pjns.v25i3.604

Dr. Muhammad Anwar Chaudary (Professor \& Chief Editor/PINS, Lahore) Dr. Saman Shahid (Associate Prof., NUCES, Lahore) 